\title{
Chicken Feed Processing Machines Using Autodesk Inventor Software
}

\section{Rancang Bangun Mesin Pengolah Pakan Ayam Menggunakan Software Autodesk Inventor}

\author{
Sabaruddin Syach ${ }^{1}$, Noer Aden Bahry ${ }^{2}$, Anis Siti Nurrohkayati ${ }^{3}$ \\ \{ sabaruddinsyach@gmail.com ${ }^{1}$, noeraden48@gmail.com², asn826@gmail.com³ \\ Program Studi Teknik Mesin, Universitas Muhammadiyah Kalimantan Timur
}

\begin{abstract}
In chicken farm, the biggest cost is from chicken feed. The feed cost is too expensive because it uses factory feed, which makes operational costs high, then the profits obtained are very small. The idea is to make the design of a chicken feed processing machine to increase the efficiency of chicken feed costs. The owner of chicken farm can produce chicken feed itself. This chicken feed processing machine is equipped with a corn grinder, dough mixer, and chicken feed mold. This chicken feed processing machine in chicken feed printing has a screw conveyor working principle that utilizes the threads of the screw as a material carrier and presses towards the end of the mold and is cut using 2 rotating blades following the screw conveyor rotation. The chicken feed processing machine uses an electric motor that has a power of $1.5 \mathrm{Hp}$ with a rotation of $140 \mathrm{rpm}$ and can produce $20.16 \mathrm{~kg} / \mathrm{hour}$ of chicken feed. This machine has dimensions of $125 \mathrm{~cm} \times 40 \mathrm{~cm} \times 80 \mathrm{~cm}$, the chicken feed processing machine designed using Autodesk Inventor software.
\end{abstract}

Keywords - chicken feed processing machine; grinding machine; mixer machine

\begin{abstract}
Abstrak. Dalam berternak ayam biaya terbesar yaitu dari pakan ayam. Biaya pakan terlalu mahal karena menggunakan pakan pabrikan, membuat biaya oprasional menjadi tinggi sehingga keuntungan yang di dapatkan sangatlah kecil. Berdasarkan permasalahan tersebut didaptakan pemikiran untuk membuat rancang bangun mesin pengolah pakan ayam untuk meningkatka efisiensi biaya pakan ayam karena dapat memproduksi pakan ayam sendiri.Mesin pengolah pakan ayam adalah sebuah alat yang dirancang untuk membuat pakan ayam. Mesin pengolah pakan ayam ini dilengkapi dengan penggiling jaggung, pengaduk adonan, dan pencetak pakan ayam. Mesin pengolah pakan ayam ini pada pencetakan pakan ayam memiliki prinsip kerja screw conveyor yang memanfaatkan ulir-ulir pada screw sebagai pembawa bahan dan menekan kearah ujung cetakan dan dipotong menggunakan 2 mata pisau yang berputar mengikuti putaran screw converyor. Mesin pengolah pakan ayam di gerakan oleh satu motor listrik yang memiliki daya 1,5 Hp dengan putaran 140 rpm dan dapat menghasilkan pakan ayam 20,16 kg/jam. Mesin ini memiliki dimensi $125 \mathrm{~cm} \times 40 \mathrm{~cm} \times 80 \mathrm{~cm}$, mesin pengolah pakan ayam di desain menggunakan software Autodesk Inventor.
\end{abstract}

Kata Kunci-mesin pengolah pakan ayam; mesin penggiling; mesin pengaduk

\section{Pendahuluan}

Perkembangan teknologi telah banyak membantu manusia memmudahkan pekerjaan disemua bidang. Dalam berternak ayam biaya terbesar didapatkan dari pakan ayam, biaya pakan terlalu mahal karna menggunakan pakan pabrikan, membuat biaya oprasional menjadi tinggi sehingga keuntungan yang didapatkan juga sedikit.

Berdasarkan masalah tersebut, maka dibuatlah proses perancangan mesin pengolah pakan ayam. Mesin pengolah pakan ayam adalah sebuah alat yang digunakan untuk membuat pakan ayam,mesin pengolah pakan ayam ini dibuat agar peternak bisa memproduksi pakan ayam sendiri maka dapat memudahkan dan meringankan biaya pakan ayam, Pakan ayam biasanya terbuat dari jagung, dedak, bungkil kedelai, pecahan gandum yang di campur menjadi adonan. Mesin pengola pakan ayam ini dilengkapi dengan pengaduk adonan, penggiling dan pencetak pakan ayam dan semua bagian mesin ini di gerakan oleh 4 pulley dan 3 v-belt yang dimana hanya satu pulley yang terhubung pada satu motor listrik. Pencetak adonan memiliki prinsip kerja screw conveyor yang memanfaatkan ulir-ulir pada screw untuk membawa adonan dan menekan kearah ujung cetakan yang berdiameter $170 \mathrm{~mm}$ dan diameter lubannya $5 \mathrm{~mm}$ sebanyak 114 lubang akan menjadikan adonan berbentuk pakan ayam, untuk ukuran pakan ayam bisa disesuaikan dengan berapa banyaknya mata pisau yang berada ujung cetakan, semakin banyak mata pisau maka semakin kecil pakan ayam yang akan terpotong.

Pada proses pengolahan pakan ayam diperlukan alat pengaduk yang digunakan untuk membentuk suatu adonan dan satu alat pencetak digunakan untuk memproduksi pakan ayam dengan ukuran yang sudah ditentukan. Mesin pencetak pakan ayam berbentuk silinder, pada bagian dalammnya terdapat ulir pengepres ini mendorong bahan adonan ke arah ujung silinder dan menekanan plat berlubang sebagai pencetak. Lubang plat menggerakan poros 
pencetak sesuai dengan ukuran yang di kehendaki, setelah itu akan terpotong oleh pisau pemotong. (Satriyo dkk, 2008).

Rancang bangun (desain) mesin pengolah pakan ayam ini diharapkan pada penggunaannya berjalan dengan lancar. Adapun alat-alat yang digunakan pada mesin pengolah pakan ayam ini yaitu motor listrik, belt dan pulley. Perubahan energy listrik menjadi energi mekanik terjadi karena arus bolak-balik yang dihasilkan oleh motor AC [1]. Belt merupakan adalah transmisi yang lebih sederhana dibandingkan dengan rantai dan roda gigi. Belt dapat di pasang pada dua buah pulley atau lebih. Pully pertama berfungsi sebagai penggerak pulley ke dua.

\section{METODE}

Metode penelitian perencanaan pembuatan mesin pengolah pakan ayam di berikan pada gambar berikut :

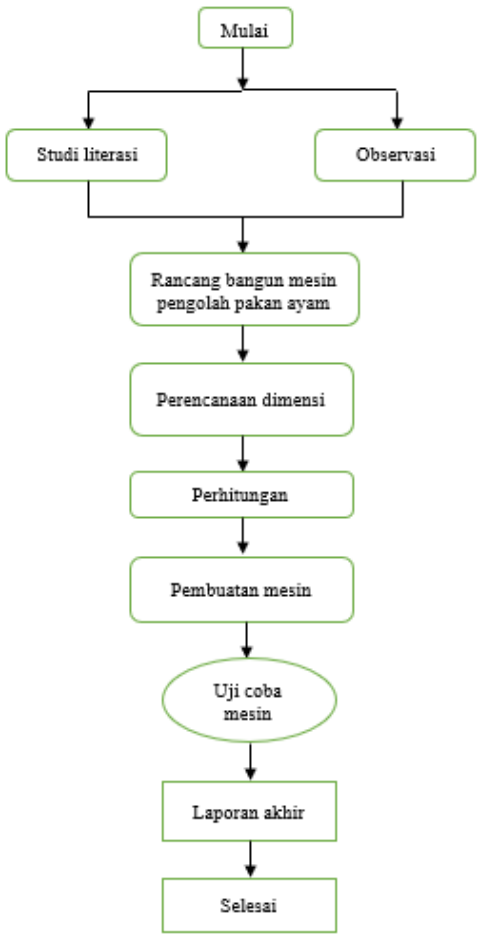

Gambar 1. Proses pembuatan mesin pengolah pakan ayam

Desain mesin pengolah pakan ayam ini menggunakan software Autodeks Inventor bertujuan untuk melakukan perencanaan dan pembuatan mesin pengolah pakan ayam. Mesin pengolah pakan ayam ini diharapkan memiliki kualitas yang lebih efisien dan lebih efektif.

Prinsip kerja mesin pengolah pakan ayam menggunkan pengerak motor listrik untuk menghasilkan energi kinetik. Selanjutnya energi kinetik yang dihasilkan dihubungkan oleh v-belt dari pulley satu ke pulley yang lain pulley yang terletak pada motor listrik lebih kecil dari pada pulley lainnya dengan reduser yang rencanakan yaitu 1:20, reduser ini berfungsi untuk memperkecil putaran yang dihasilkan oleh motor listrik.

Pengaduk ini terhubung oleh pulley 3 yang diputar oleh pulley 2 dan pulley 2 terhubung oleh pulley 1 dimana pulley 1 digerakan oleh motor listrik. Pengaduk ini berputar horizontal, dimana pengaduk ini berfungsi mencampur bahan bahan yang di gunakan untuk membuat pakan ayam setelah pakan ayam tercampur dan berbentuk adonan buka tutup pengaduk agar adonan jatuh ke mesin pencetak pakan ayam. 


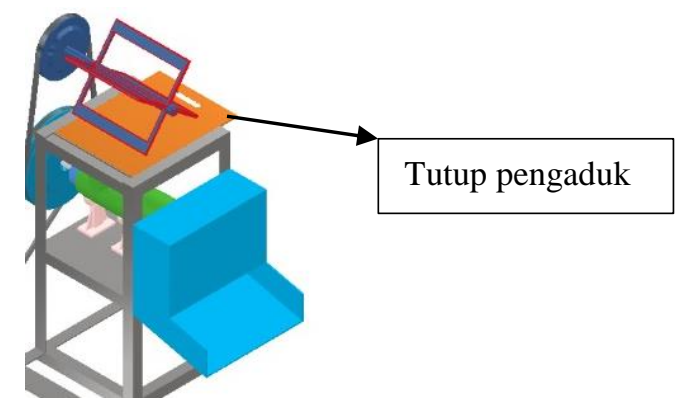

Gambar 1. Tutup pengaduk

Screw conveyor yang terhubung dengan pulley maka screw converyor akan berputar sehingga adonan akan terdorong keujung cetakan dan akan terpotong oleh pisau yang ada di depan cetakan

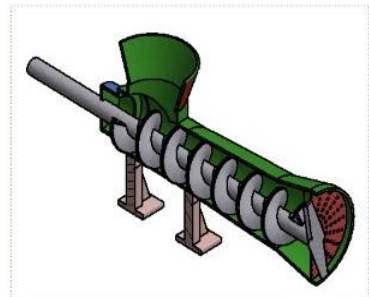

Gambar 2. Screw conveyor

Rencana Diameter dari cetakan ini yaitu $170 \mathrm{~mm}$ dan dia meter lubang pada cetakan yaitu $5 \mathrm{~mm}$ banyak lubang pada cetakan yaitu 114 lubang ketika screw converyor mendorong adonan ke ujung cetakan maka adonan akan keluar dari cetakan dan rencana menggunakan 2 mata pisau untuk proses pemotongannya, ketika pisau berputar $180^{\circ}$ maka pakan ayam yang sudah di cetak akan terpotong sebanyak 114 potongan

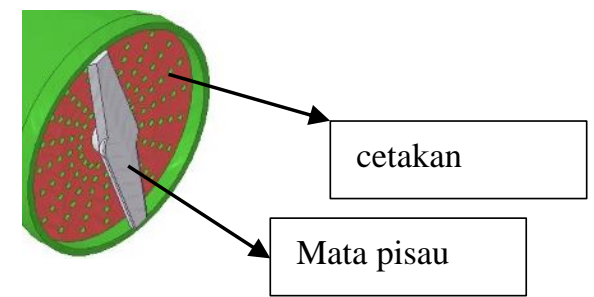

Gambar 3. Cetakan dan mata pisau

Mesin ini bekerja dimana jika mesin dinyalakan maka pulley 1 yang terhubung oleh motor akan memutar pulley 2 yang terhubung oleh poros screw converyor pencetak pakan ayam dan pulley 4 yang terhubung ke poros penggiling yang terikat oleh v-belt dan pulley 2 akan memutar pully 3 yang terhubung pada poros pengaduk yang terikat oleh v-belt jadi jika mesin dinyalakan maka semua komponen seperti pengaduk, pencetak dan penggiling akan bekerja. Rencana diameter pulley yang digunakan yaitu :

Table 1. Rencana diameter pulley yang digunakan

\begin{tabular}{ccc}
\hline No & Pulley & Diameter \\
\hline 1 & Pulley 1 & $107 \mathrm{~mm}$ \\
\hline 2 & Pulley 2 & $307 \mathrm{~mm}$ \\
\hline 3 & Pulley 3 & $207 \mathrm{~mm}$ \\
\hline 4 & Pulley 4 & $190 \mathrm{~mm}$ \\
\hline
\end{tabular}


Procedia of Engineering and Life Science Vol.1 No. 1 March 2021

Seminar Nasional \& Call for Paper Fakultas Sains dan Teknologi (SENASAINS 1st)

Universitas Muhammadiyah Sidoarjo

Rencana Panjang v-belt yang digunakan yaitu :

Table 2. Rencana panjang v-belt yang digunakan

\begin{tabular}{ccc}
\hline No & Pulley & Panjang v-belt \\
\hline 1 & Pulley 1 ke pulley 2 & $570 \mathrm{~mm}$ \\
\hline 2 & Pulley 2 ke pulley 3 & $394 \mathrm{~mm}$ \\
\hline 3 & Pulley 1 ke pulley 4 & $695 \mathrm{~mm}$ \\
\hline
\end{tabular}

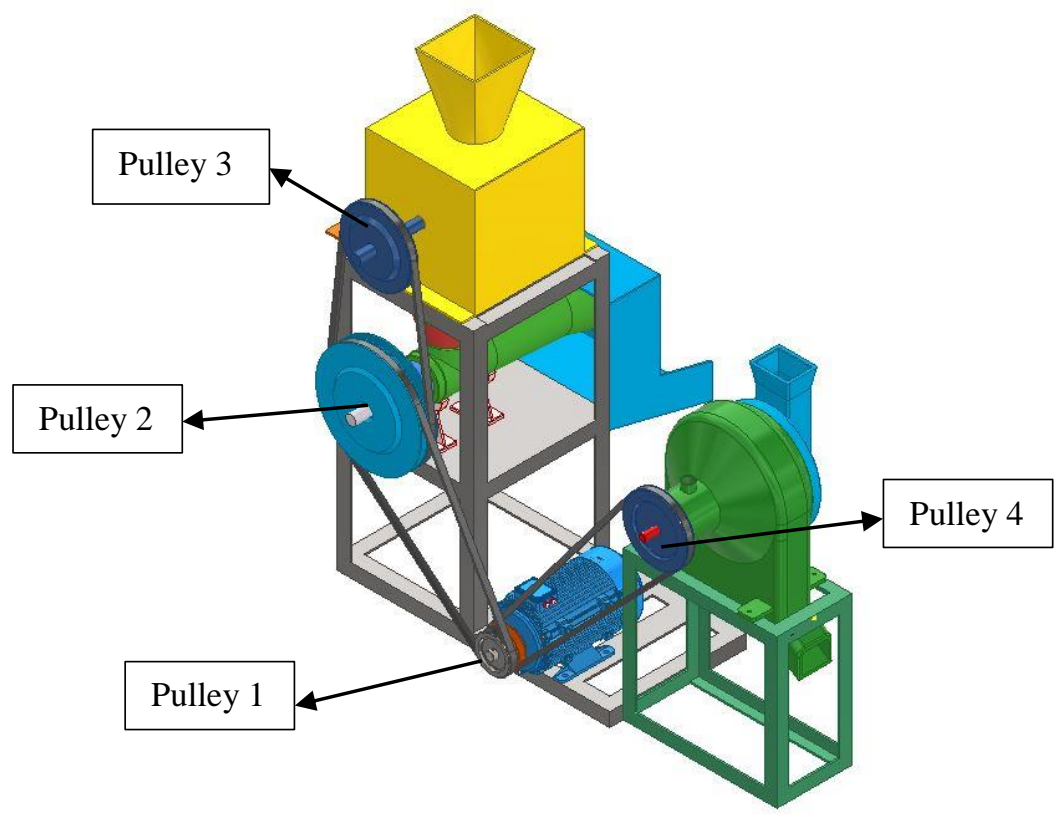

Gambar 4. Desain mesin pengolah pakan ayam

\section{Hasil dan Pembahasan}

Pada rancang bangun mesin pengola pakan ayam ini di desain menggunakan software Autodeks Inventor dan pengola pakan ayam ini menngunakan system trasnmisi yang lebih sederhana yaitu belt, belt yang digunakan yaitu jenis belt tipe $\mathrm{v}$-belt jenis $\mathrm{v}$-belt ini memiliki gaya gesek yang lebih besar dibandingkan dengan betl tipe yang lainnya , v-belt ini dinilai lebih ekonomis atau murah mengingat komponen ini mudah untuk dicari penggantinya jika terjadi kerusakan pada v-belt sebelumnya.

Pada mesin yang sudah ada di pasaran biasanya kecepatan putran mesin yaitu sebesar 600 Rpm, 1400 Rpm, 1440 Rpm. Jika kecepatan puran mesin pengolah pakan ayam di rencanakan $1400 \mathrm{Rpm}$, maka daya yang dibutuhkan dengan besar torsi yang direncanakan yaitu $80 \mathrm{~kg} \mathrm{~cm}$ sehingga dapat dihitung dengan persamaan sebagai berikut :

$$
\mathrm{P}(\mathrm{HP})=\frac{T(l b f \cdot f t) \times n(R p m)}{5250}
$$

Dimana :

$$
\begin{aligned}
& \mathrm{P}=\text { Daya }(\mathrm{HP}) \\
& \mathrm{n}=\operatorname{kecepatan} \text { Putaran }(\mathrm{Rpm}) \\
& \mathrm{T}=\text { Torsi (lbf.ft) }
\end{aligned}
$$

Jika : $1 \mathrm{~kg} \mathrm{~cm}=0,0723301 \mathrm{lb}-\mathrm{ft}$

$80 \mathrm{~kg} \mathrm{~cm}=80 \mathrm{~kg} \mathrm{~cm} \times 2,20462 \mathrm{lb} / \mathrm{kg} \times 0,0328084 \mathrm{ft} / \mathrm{cm}$

$$
=5,786 \mathrm{lb}-\mathrm{ft}
$$

Maka :

$$
\begin{aligned}
\mathrm{P}(\mathrm{HP}) & =\frac{\mathrm{T}(\mathrm{lb} . \mathrm{ft}) \times n(\mathrm{Rpm})}{5250} \\
& =\frac{5,786(\mathrm{lbf} . \mathrm{ft}) \times 1400(\mathrm{Rpm})}{5250} \\
& =1,5 \mathrm{HP}
\end{aligned}
$$

Jadi, perencana awal motor yang akan digunakan minimal 1,5 HP 
Gaya yang bekerja pada poros

Dimana daya motor yang direncanakan yaitu sebesar $1,5 \mathrm{Hp}$, putaran poros yaitu $1400 \mathrm{rpm}$ dan factor koreksi yang digunakan yaitu $\mathrm{fc}=1$ sehigga dapat dihitung perencanaan daya [2]

Daya motor $(\mathrm{P})=\mathrm{Hp} \times 0,746$

$$
\begin{aligned}
& =1,5 \times 0,746 \\
& =1,119 \mathrm{kw} \\
\mathrm{P}_{\mathrm{d}} & =\mathrm{fc} \times \mathrm{P} \\
& =1 \times 1,119 \\
& =1,119 \mathrm{Kw}
\end{aligned}
$$

\section{Perhitungan jumlah putaran}

Dimana kecepatan putaran awal mesin pengolah pakan ayam ini sebesar $1400 \mathrm{Rpm}$ dan reduser 1:0 sehingga dapat dihitung jumlah putaran yang dihasilkan :

$$
\begin{aligned}
\mathrm{N}_{2} & =\mathrm{N}_{1}: \text { ration } \\
& =1400: 10 \\
& =140 \mathrm{Rpm}
\end{aligned}
$$

Perencanaan belt dan pulley yang akan digunakan yaitu

Kecepatan keliling pulley [3] :

$$
\begin{aligned}
\mathrm{V} & =\frac{\pi \cdot D 1 \cdot \mathrm{n} 1}{60 \times 1000} \\
& =\frac{3,14 \times 107 \times 140}{60000} \\
& =0,784 \mathrm{~m} / \mathrm{s}
\end{aligned}
$$

Gaya keliling belt [4]:

$$
\begin{aligned}
\mathrm{P}_{\text {rated }} & =\frac{102 \times \mathrm{N}}{\mathrm{V}} \\
\mathrm{P}_{\text {rated }} & =\frac{102 \times 1,119}{0,784} \\
& =145,584 \mathrm{kgf}
\end{aligned}
$$

\section{Panjang belt}

Perencanaan Panjang belt dari pulley 1 ke pulley 2 sebagai berikut [5]

$$
\begin{aligned}
\mathrm{L} & =2 \cdot \mathrm{a}+\frac{\pi}{2}\left(\mathrm{D}_{2}+\mathrm{D}_{1}\right)+\frac{(\mathrm{D} 2-\mathrm{D} 1)^{2}}{4 \cdot \mathrm{a}} \\
\mathrm{L} & =2 \times 570 \mathrm{~mm}+\frac{3,14}{2}(307+107)+\frac{(307-107)^{2}}{4 \times 570} \\
& =1140+649,98+17,544 \\
& =1807,524 \mathrm{~mm}
\end{aligned}
$$

Perencanaan belt dari pulley 1 ke pulley 4 sebagai berikut

$$
\begin{aligned}
\mathrm{L} & =2 \cdot \mathrm{a}+\frac{\pi}{2}\left(\mathrm{D}_{2}+\mathrm{D}_{1}\right)+\frac{(\mathrm{D} 2-\mathrm{D} 1)^{2}}{4 \cdot \mathrm{a}} \\
\mathrm{L} & =2 \times 695 \mathrm{~mm}+\frac{3,14}{2}(190+107)+\frac{(190-107)}{4 \times 695} \\
& =1390+466,29+2,478 \\
& =1858,768 \mathrm{~mm}
\end{aligned}
$$

Perencanaan belt dari pulley 2 ke pulley 3

$$
\begin{aligned}
\mathrm{L} & =2 \cdot \mathrm{a}+\frac{\pi}{2}\left(\mathrm{D}_{2}+\mathrm{D}_{1}\right)+\frac{(\mathrm{D} 2-\mathrm{D} 1)^{2}}{4 \cdot \mathrm{a}} \\
\mathrm{L} & =2 \times 394 \mathrm{~mm}+\frac{3,14}{2}(207+307)+\frac{(207-307)}{4 \times 394} \\
& =788+806,98+6,345 \\
& =1601,325 \mathrm{~mm}
\end{aligned}
$$




\section{Kapasitas potongan}

Putaran motor sebanyak 1400 melewati reducer 1:10 maka putaran motor menjadi 140 Rpm

Direncanakan kapasitas mesin dicari dengan perhitungan sebagai berikut :

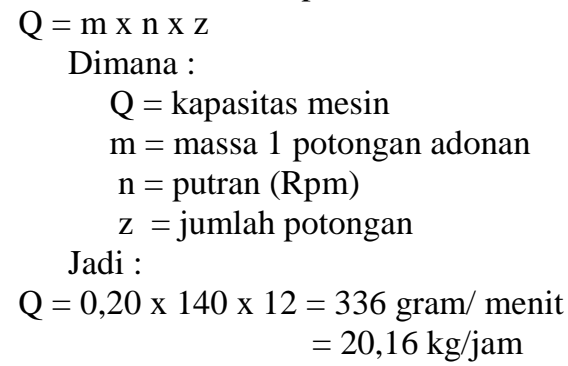

\section{KESIMPULAN}

Mesin pengolah pakan ayam ini menggunakan daya motor yaitu 1,5 HP dengan kecepatan putaran $1400 \mathrm{Rpm}$. Rasio speed reduser yang akan digunakan yaitu 1:10. Diameter pulley yang akan digunakan pulley $1=107 \mathrm{~mm}$ pulley $2=307 \mathrm{~mm}$ pulley $3=207 \mathrm{~mm}$ dan pulley $4=190 \mathrm{~mm}$. Jenis belt yang akan digunakan yaitu v-belt dengan Panjang belt dari pulley 1 ke pully $2=1807,524 \mathrm{~mm}$, pulley 2 ke pulley $3=1601,325 \mathrm{~mm}$, dan dari pully $1 \mathrm{ke}$ pulley $4=1858,768 \mathrm{~mm}$. Estimasi kapasitas mesin yaitu : 20,16 kg/jam.

\section{UCAPAN TERIMA KASIH}

Kami ucapkan terimakasih pada dosen program studi S1 Teknik Mesin universitas Muhammadiyah Kalimantan Timur yang membantu memberi masukan agar tersusunnya paper ini dan terimaksih kepada Mahasiswa yang berperan dalam mendesain mesin pengolah pakan ayam ini dan kami ucapkan terimaksaih kepada semua pihak yang yang telah membantu tersusunya paper ini.

\section{REFERENSI}

[1] A. S. Nurrohkayati, "Desain Mesin Perajang Singkong Menggunakan Cakram 4 Mata Pisau dengan," TEKNOKA, pp. 2502-8782, 2020.

[2] S. Nugroho, "Rancang Bangun Mesin Pencetak Pellet dari Limbah Telur Menjadi Pakan," Artikel Skripsi, 2018.

[3] D. Zulrahman, "Rancang Bangun Mesin Pencacah Kulit Singkong Dan Kulit Pisang Sebagai Bahan Dasar Pupuk Organik," Prisiding Seminar Nasional Unimus, 2020.

[4] S. Ramadhani, "Desain Mesin Perajang Pisang Sebagai Upaya Meningkatkan Produktivitas IRT Kripik Pisang," Prosiding Seminar Nasional Unimus, 2020.

[5] N. Mataram, "Perancangan Mesin Spinner Peniris Minyak Untuk Olahan Keripik Dengan Menggunakan software Dassault Systemes Soliwork," Prosiding Seminar Nasional Unimus, 2020.

[6] Zikri.2008. Rancang Bangun Mesin Pembuat Pelet Untuk Pakan Ternak.Tugas Akhir. Padang: Politeknik Universitas Andalas.

[7] Satriyo BA, dkk. 2008. Balai Besar Pengembangan Mekanisasi Pertanian Situgadung. Legok.Tanggerang. http://www.cabi.net.id. 